\title{
HUBUNGAN KETERGANTUNGAN PROSES ANTARA PROSES SPLITTING DAN DISTILASI PADA INDUSTRI OLEOKIMIA
}

\author{
Muhammad Yusuf Ritonga \\ Departemen Teknik Kimia, Fakultas Teknik, Universitas Sumatera Utara, Medan 20155, Indonesia \\ Email: yusufrit@gmail.com
}

\begin{abstract}
Abstrak
Target tingkat produksi normal suatu distillat asam lemak (DAL) atau Distillat Asam Lemak Minyak Kelapa Sawit (DALMKS) gagal untuk dicapai dan mendorong untuk melakukan suatau analisa dan studi - menyelesaikan masalah ini pada skala industri. DALMKS dibuat melalui proses degumming, splitting dan distillasi. Tingkat produksi ditingkatkan pada studi ini dengan metode trial and error. Tingkat hidorolisa splitting yang ditingkatkan - menjadi $98 \%$ sangat membantu menaikkan tingkat produksi DALMKS menjadi $93 \%$ (target normal). Fakta ini menunjukkan terdapat hubungan antar proses yang sangat kuat antara proses splitting dan distillasi.
\end{abstract}

Kata kunci : tingkat hidrolisa, hidrolisa, tingkat produksi, target, distillasi.

\begin{abstract}
The normal production yield target of a fatty acid distillated products (FADP) or DPOFA (Distilled Palm Oil Fatty Acid)'s fail to be achieved, and lead to do a particular analysis and study - to solve the problem in industrial scale. The DPOFA's manufactured through degumming, splitting and distillation processs. The production yield's improved in this study by using trial and error method. The improved splitting degree (98\% minimum) helped much better DPOFA production yield - come to be $93 \%$ (normal target). There are strong processes interrelationship between splitting and distillation process.
\end{abstract}

Keywords : splitting degree, hydrolysis, production yield, target, distillation

\section{Pendahuluan}

Pada proses diversifikasi pembuatan dan pemurnian produk asan lemak (AL) DPOFA ditemukan kesulitan untuk mendapatkan target tingkat produksinya (production yield) di bawah normal, khususnya pada proses distillasi. Kondisi ini menyebabkan kapasitas dan jadwal produksi AL lemak terganggu. Tingkat produksi AL turun signifikan [9]. Masalah ini selalu timbul pada distilasi AL, relatif beberapa waktu setelah terjadi masalah penurunan tingkat hidrolisa (splitting degree, $S D$ ) minyak kelapa sawit (Crude Palm Oil, CPO). Masalah ini juga menyebabkan mutu DPOFA yang dihasilkan menurun, tapi tidak disinggung dalam artikel ini.

\section{Teori}

Tahapan proses pembuatan DPOFA

Pembuatan produk AL ini mengikuti alur proses ; degumming (memisahkan trace logam dan gum dari CPO), splitting (konversi CPO menjadi asam lemak Splitted Palm Oil Fatty Acid, atau SCPOFA) [4] dan destillasi. Tahap akhir ini untuk memisahkan bahan penyebab warna salah satunya [7]. Juga memisahkan bahan - bahan bertitik didih lebih rendah dari $\mathrm{C}_{16}$ dan lebih tinggi dari
$\mathrm{C}_{18}$ ) dari SCPOFA (umpan distillasi), untuk menghasilkan DPOFA. Semua bahan - bahan ini terkandung dalam $\mathrm{CPO}$, tentu juga SCPOFA.

Hidrolisa minyak kelapa sawit

Minyak kelapa sawit (trigliserida) yang dihidrolisa sesuai reaksi yang umum berlaku pada minyak \& lemak (MDL), pada suhu 250 - $260{ }^{\circ} \mathrm{C}$ dan 55 bar [5]. Dilakukan dengan air berlebih. Reaksi hidrolisa, adalah reaksi keseimbangan dengan mekanisma ditampilkan di bawah ini [11]. Terjadi pembentukan parsial gliserida(glsd); di -, mono gliserida dan sisa trigliserida.

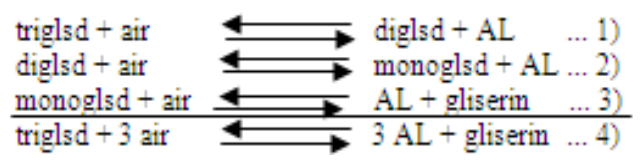

Tingkat hidrolisa dan masalahnya

Tingkat hidrolisa menyatakan jumlah AL yang terbentuk pada hidrolisa MDL dan dinyatakan dengan hubungan matematik sederhana $\{\mathrm{SD}=$ Bilangan asam, (AV)/Bilangan penyabunan (SV) $\}$ [5]. Ini juga menyatakan jumlah bagian MDL yang berubah menjadi AL pada hidrolisa MDL. 
Tingkat hidrolisa yang cenderung tinggi menyatakan jumlah AL terbentuk juga semakin banyak pada hidrolisa demikian sebaliknya atau MDL tersisa cenderung semakin rendah. Tingkat hidrolisa yang tinggi, adalah suatu keberhasilan, sebaliknya merupakan suatu kegagalan atau masalah proses produksi oleo kimia. Target tingkat hidrolisa yang umum, adalah $98 \%$ minimum [5,9]. Sedikit penurunan di bawah nilai ini, merupakan awal masalah dalam hidrolisa. Penurunan tingkat hidrolisa selalu disertai dengan kenaikan level kadar air pada AL yang dihasilkan, karena air yang disupplai tidak terpakai dan terpisahkan dengan baik pada reaktor hidrolisa (splitter). Hal ini disebabkan kegagalan satu atau beberapa berbagai faktor pedukung reaksi hidrolisa (tidak dibahas dalam artikel ini). Kenaikan kadar air ini menyebabkan kemurnian umpan AL yang digunakan untuk destillasi berkurang.

Titik didih asam lemak dalam campuranasam lemak dan (MDL)

Asam lemak dapat bercampur dalam segala proporsi dengan MD L. Dengan demikian AL hasil hidrolisa dan MDL sisa hidrolisa (dalam bentuk tri-, di -dan monogliserida - lihat reaksi 1 hingga 3 di atas) bercampur dengan baik. Keduanya dapat dipisahkan dengan distillasi. Trigliserida $\left\{\mathrm{C}_{3} \mathrm{H}_{5}(\mathrm{OOCR})\right\}$ merupakan ester dari gliserin $\left(\mathrm{C}_{3} \mathrm{H}_{8} \mathrm{O}_{3}\right)$ dan $\mathrm{AL}(\mathrm{R}-\mathrm{COOH})$, rasio 1 : 3 . Berdasarkan hal ini trigliserida mempunya titik didih (Td) yang lebih tinggi dari AL dengan gusus alkil (R) yang sama. Dengan demikian hidrolisa MDL yang menghasilkan AL kasar memiliki Td yang lebih rendah dari MDL asal, juga dari di -dan mono- gliserida, sebab dipisahkan dari gliserin. Jika AL mengandung lebih banyak sisa MDL, Td campuran ini akan bertambah atau jika sebaliknya, Td campuran ini lebih tinggi, demikian sebaliknya. Analog dengan kenaikan Td AL, karena kenaikan jumlah AL yang ber - Td lebih tinggi $[3,6]$.

\section{Perubahan performa distillasi}

Kondisi proses destillasi asam lemak selalu direncanakan sesuai karakter AL murni (kadar air 0,1 \% maksimum dan kadar MDL $3 \%$ maksimum) untuk mengolah dan memurnikan AL, demikian juga pendukung proses destillasi. Perubahan pada karakter AL umpan yang dipakai pada proses destillasi akan menyebabkan perubahan performa destillasi. Ini sesuai teori destillasi [1,8]. Perubahan karakter umpan, karena SD menurun pada masalah hidrolisa di atas. Hal ini diperkirakan akan berdampak pada penurunan memperoleh jumlah asam lemak yang akan diperoleh (production yield), cenderung lebih rendah. Bukankah jumlah AL berkurang, MDL bertambah, karena SD menurun. Kenaikan jumlah sisa MDL pada umpan AL destillasi akan menyulitkan pemisahan AL dari pada umpan AL (campuran asam lemak dan MDL), diperlukan suhu pemanas dan kapasitas pemanas yang lebih tinggi. Kesulitan memisahkan AL akan semakin tinggi, disebabkan kenaikan kadar air pada umpan AL SCPOFA. Air memiliki titik didih yang jauh lebih rendah dari AL [12]. Asam lemak dipisahkan pada suhu di atas $200{ }^{\circ} \mathrm{C}$. Pada suhu ini dan tekanan vakum air menguap dengan sangat cepat dan membuat tekanan vakum sangat labil, menurunkan tekanan vakum. Pemisahan AL tidak bisa dilakukan dengan baik dan akan mengurangi perolehan AL.

Bisakan analisa ini menjawab masalah yang timbul? Untuk menjawab ini harus dilakukan studi langsung, research terkait splitting dan destillasi berbasis CPO.

\section{Metodologi Penelitian}

Bahan yang dipergunakan pada studi ini, adalah CPO (bilangan penyabunan SV $206 \mathrm{mg} \mathrm{KOH} / \mathrm{g}$ ), SCPOFA (Splitted CPO Fatty Acid), uap bertekanan 55 bar, 12 bar, 6 bar, air pendingin $30{ }^{\circ} \mathrm{C}, 55{ }^{\circ} \mathrm{C}$ dan Oil thermal heater. Metode yang digunakan, adalah metode trial and error. Bilangan penyabunan (SV) dianalisa dengan AOCS Official method No.Cd 3 - 25 dan bilangan asam (AV) dengan AOCS Official method No. Te 1A -64 [2].

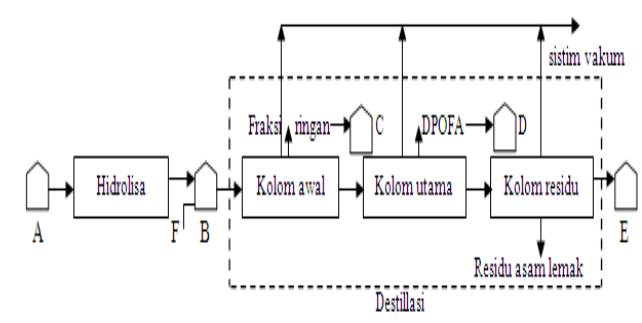

Gambar 1. Diagram alir percobaan. Ket: $\mathrm{A}=$ tangki CPO, $\mathrm{B}=$ tangki SCPOFA, $\mathrm{C}=$ tangki fraksi ringan, $D=$ tangki DPOFA, $E=$ tangki residu $A L, F=$ jalur drain air tangki SCPOFA (destillasi gaya Feld and Hanh) [9]. 
Prosedur

Tingkat hidrolisa CPO lebih dulu dicoba untuk diperbaiki dan dipertahankan $98 \%$ minimum.

1. Kapasitas pemakaian umpan SCPOFA pada destillasi dibuat lebih rendah dari produksi SCPOFA pada bagian hidrolisa. Ini mencoba untuk menaikkan AV umpan SCPOFA.

2. Air pada tangki SCPOFA selalu dibuang dari dasar tangki, hingga habis, mencoba mengurangi beban tekanan vakum destilasi.

3. Diambil dan dianalisa AV umpan distillasi tiap 4 jam, sesuai waktu reaksi hidrolisa. Mixer pada tangki umpan selalu aktif beroperasi, dicoba menaikkan AV umpan secara merata.

4. Kondisi destillasi dicoba dan dijaga tetap pada kapasitas rendah dan normal. Bilangan asam (AV) residu AL dianalisa tiap 4 jam dan dicatat. Berproduksi sambil membilas unit ini.

5. Dicoba untuk melakukan penambahan kapasitas umpan, jika terjadi kenaikan indikasi tingkat perolehan DPOFA dan/atau AV residu AL berkurang dan/atau AV SCPOFA bertambah. Ini berarti kondisi membaik. Tingkat produksi DPOFA dan residu AL dicatat tiap 2 jam

6. Langkah ke -5 dilakukan sampai kapasitas destillasi seimbang dengan hidrolisa CPO. Indikasi Makin mendekati akhir paska pembilasan dan produksi makin mengarah ke kondisi normal.

Dibuat trend grafik, terutama antara data kenaikan AV SCPOFA dan tingkat produksi DPOFA dan dianalisa. Ini berguna untuk melihat hubungan proses hidrolisa dengan destillasi.

\section{Hasil}

Perubahan perbaikan AV SCPOFA pada tangki umpan destillasi, tingkat produksi DPOFA dan AV residu AL dapat diperhatikan pada Tabel 1. Satuan AV dalam mg KOH/g. Kenaikan AV SCPOFA berdampak pada kenaikan tingkat produksi DPOFA. Kenaikan tingkat produksi DPOFA berdampak pada penurunan tingkat produksi serta $\mathrm{AV}$ residu asam lemak, yang sangat diharapkan pada destillasi asam lemak.

Keadaan ini diperoleh dengan relatif tetap mempertahankan suhu destillasi pada kisaran standar. Tekanan vakum cederung lebih rendah (tidak ditunjukkan dalam artikel ini), karena kenaikan AV SCPOFA mengurangi kadar air dalam umpan SCPOFA, sehingga beban ejektor vakum (alat pembuat vakum) lebih rendah. Tekanan vakum yang lebih rendah ke arah $3-5$ mbar (standar normal) pada kolom utama, ke arah $1-3$ mbar pada kolom residu membuat asam lemak DPOFA lebih banyak teruapkan serta mengurangi tingkat produksi dan AV asam lemak residu. Kenaikan AV SCPOPFA juga menyebabkan sisa gliserida semakin sedikit dalam SCPOFA dan berdampak pada penurunan titik didih SCPOFA. Penurunan titik didih ini juga menyebabkan DPOFA lebih banyak teruapkan pada suhu destillasi yang relatif tetap dijaga. Pada data terakhir (no. 9) merupakan akhir paska pembilasan peralatan destillasi dengan SCPOFA, sehingga diperoleh tingkat produksi DPOFA dan AV residu AL sesuai standar - diperoleh kondisi normal destillasi. Kenaikan AV SCPOFA berdampak positif bagi kondisi dan tingkat produksi DPOFA.

Tabel 1. Data - data SD hidrolisa, AV SCPOFA, tingkat produksi DPOFA dan AV residu AL

\begin{tabular}{|c|c|c|c|c|c|c|}
\hline \multirow{2}{*}{$\begin{array}{l}\mathrm{N} \\
\mathrm{o}\end{array}$} & \multirow{2}{*}{$\begin{array}{c}\text { SD } \\
\text { hidrol } \\
\text { isa } \\
(\%)^{*}\end{array}$} & \multicolumn{2}{|c|}{ SCPOFA } & \multirow{2}{*}{$\begin{array}{c}\text { Tingk } \\
\text { at } \\
\text { produ } \\
\text { ksi } \\
\\
\text { DPOF } \\
\text { A (\%) }\end{array}$} & \multirow{2}{*}{$\begin{array}{c}\text { Tingkat } \\
\text { produksi } \\
\text { residu } \\
\text { asam } \\
\text { lemak } \\
(\%)\end{array}$} & \multirow{2}{*}{$\begin{array}{c}\text { AV } \\
\text { residu } \\
\text { asam } \\
\text { lemak } \\
*\end{array}$} \\
\hline & & $\mathrm{AV}$ & $\begin{array}{l}\text { SD } \\
(\%)^{*}\end{array}$ & & & \\
\hline 1 & 98,0 & 197,8 & 96,02 & 87,0 & 11,5 & 86,0 \\
\hline 2 & 98,5 & 198,0 & 96,12 & 88,2 & 10,3 & 77,0 \\
\hline 3 & 98,0 & 198,5 & 96,34 & 89,1 & 9,4 & 70,3 \\
\hline 4 & 99,0 & 199,5 & 96,84 & 90,0 & 8,5 & 63,6 \\
\hline 5 & 99,0 & 201,5 & 97,81 & 90,3 & 8,2 & 61,4 \\
\hline 6 & 98,5 & 202,0 & 98,06 & 91.5 & 7,0 & 52,4 \\
\hline 7 & 98,5 & 203,0 & 98,54 & 92,0 & 6,5 & 48,7 \\
\hline 8 & 98,5 & 203,0 & 98,54 & 92,5 & 6,0 & 45,0 \\
\hline 9 & 99,0 & 203,0 & 98,54 & 93,0 & 5,5 & 40,0 \\
\hline
\end{tabular}

Catatan : *Target standar ; SD $=98 \%$ minimum, $\mathrm{AV}=20-40 \mathrm{mg} \mathrm{KOH} / \mathrm{g}$ [10]

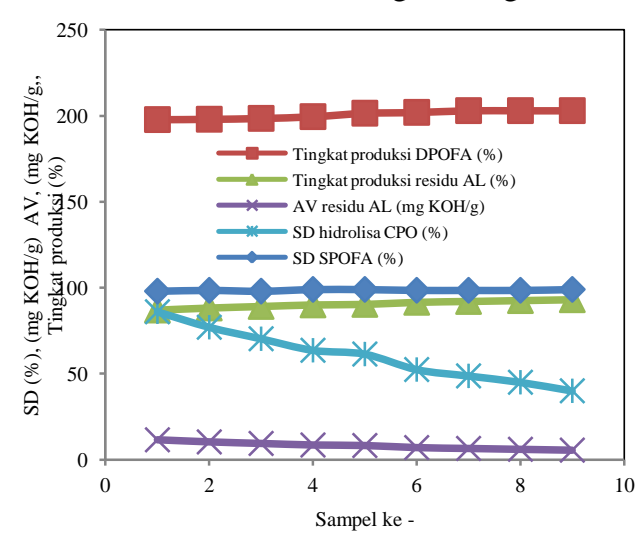

Gambar 2. Kecenderungan perbaikan SD SCPOFA \& hidrolisa, tingkat produksi DPOFA \& residu, AV residu AL. Indikasi hubungan yang kuat antara proses hidrolisa dan destillasi. 


\section{Kesimpulan}

Hubungan antara proses hidrolisa dan destillas sangat kuat. Sangat disarankan menggunakan dua tangki penyimpan bagi produk intermediat SCPOFA, umpan destillasi. Jika terjadi gangguan penurunan SD hidrolisa CPO, SCPOFA dapat dialihkan dan disimpan pada tangki penyimpan kedua dan destillasi terus menghasilkan DPOFA dengan tingkat produksi yang normal sesuai target dan tanpa menggangu jadwal produksi, dari tangki penyimpan pertama (AV yang sesuai target normal). Bilangan asam SCPOFA pada tangki penyimpan kedua dapat diperbaiki dengan salah salah satu metode, trial and error, seperti yang dilakukan pada studi ini.

\section{Ucapan terimakasih}

Ucapan terimakasih disampaikan kepada PT. FSC yang telah mengizinkan dan memfasilitasi penulis untuk melakukan dan menyelesaikan studi diversifikasi produk ini.

\section{Daftar Pustaka}

[1] A. Kayode Coker, Ludwig's applied process design for chemical and petrochemical plants, Volume 1, Fourth Edition, Gulf Professional Publishing, Burlington, MA 01803, USA, 2007

[2] David. F., Official Method And Recommended Practices of the AOCS, $5^{\text {th }}$ Edition, 2nd Printing. AOCS Press, USA, 2006.

[3] Fereidoon Shahidi, Bailey's Industrial Oil and Fat Products, 6th edition. John Wiley \& Sons, Hoboken, N.J, 2005,.

[4] Feld and HanH GmbH., Splitting, PT. FSC, Medan, 1998.

[5] Greeven, Oil Pretreatment and Spilitting, Lurgi. GmbH, Jakarta, Indonesia,1990.

[6] Ketaren. S., Minyak dan Lemak Pangan, UI Press, Jakarta, 2009.

[7] Muhammad Yusuf. R., Optimasi Pembuatan Asam Stearat Berbasis Refined Bleached Deodorized Palm Stearin (RBDPS) Yang Stabil Sesuai Standar Mutu, Disertasi Doktor, FMIPA, USU, Medan, Hal. 24, 2010.

[8] Muhammad Yususf. R., Optimising refined bleached deodorized palm stearin for its crude stearic acid iodine value to provide the stable specification of blended stearic acid distillate iodine value, Indian Journal of Science and Technology. 5 (9) (Sep. 2012), Hal. 3296, 2012.

[9] PT. FSC, Fatty Acid Plant Production Report, Tg. Morawa, Medan, 2004.
[10] PT. FSC, Daily Process \& Utility Analysis Report, Quality Assurance, Tg. Morawa, Medan, 2004.

[11] Rolf Brockmann, Gunter Demmering, Udo Kreutzer, Manfred Lindemann, Jurgen Platinka, Udo Steinberner, Fatty Acids, Henkel KGaA, Federal Republic of German. 1987.

[12] Unichema International, Fatty Acid Data Book, 2nd Edition, Frankfurt, Republic Federal German, 1998. 